Original Research Paper

\title{
$\beta$-Glucans and Probiotics
}

\author{
${ }^{1}$ Mattia Pia Arena, ${ }^{1}$ Giuseppe Spano and ${ }^{2}$ Daniela Fiocco \\ ${ }^{I}$ Department of Science of Agriculture, \\ Food and Environment, University of Foggia, Via Napoli 25, Foggia, 71122, Italy \\ ${ }^{2}$ Department of Clinical and Experimental Medicine, University of Foggia, Via Napoli 20, Foggia, 71122, Italy
}

Article history

Received: 15-11-2016

Revised: $18-01-2017$

Accepted: 29-03-2017

Corresponding Author: Giuseppe Spano

Department of Science of

Agriculture, Food and

Environment, University of

Foggia, Via Napoli 25, Foggia,

71122, Italy

Fax: $+39(0) 881740211$

Tell: $+39(0) 881589303$

Email: giuseppe.spano@unifg.it

\begin{abstract}
In the recent decades, several health-promoting features have been ascribed to $\beta$-glucans. Biological properties such as anti-cancer, antiinflammatory and immune-modulating activity have been claimed for these polysaccharides. Moreover, when $\beta$-glucans were used in association with probiotic bacteria, prebiotic effects have been demonstrated, due to their ability to enhance growth, metabolism and/or beneficial activities of probiotics. This review shall present an overview of those studies, which have documented the diverse health-benefits of $\beta$-glucans and their association with probiotics.
\end{abstract}

Keywords: $\beta$-Glucans, Probiotic, Prebiotic, Synbiotic, Immune-Modulation

\section{Introduction}

\section{Chemistry and Occurrence of $\beta$-Glucans}

$\beta$-Glucans are long chain complex carbohydrates which can be found in cereals, seaweeds, mushrooms, yeast and in some bacteria. From a chemical point of view, $\beta$-glucans are glucose polymers consisting of linear D-glucose core chains which can contain up to 250,000 glucose residues linked by $\beta$-glycosidic bonds. Such core can be branched by further side chains of sugar, whose characteristic branching depends on the source (Vannucci et al., 2013). For example, the chemical structure of $\beta$-glucans isolated from bacteria is a simple linear $\beta(1,3)$-D-glycopyranosyl polymer with none, or sometimes limited, $\beta(1,3)$ - and $\beta(1,2)$-D-glycopyranosyl branch chains (Lam and Cheung, 2013). Members of the Agrobacterium genera, produce linear $\beta$-glucans, commonly known as Curdlan, which can contain up to 12,000 glucose units and is biosynthesized during the post-stationary growth phase (Futatsuyama et al., 1999; Kim et al., 2003). However, also cyclic $\beta(1,3)-$ and $\beta(1,6)$ - D-glycopyranosyl linked glucans have been isolated from bacteria, e.g., from several plant-symbiotic bacterial species including Bradyrhizobium japonicum and Rhizobium loti, in which the cyclic structure seems to play a role in their symbiotic association with plant, helping the nodulation forming (Gay-Fraret et al., 2012). The cyclic structure of these compounds is given by two $\beta(1,3)$-linked trisaccharides interrelated through two $\beta(1,6)$-linked trisaccharides presenting none or a single side branch linked to free C6 (Komaniecka and Choma, 2003). Furthermore, Streptococcus pneumoniae synthesizes branched $\beta$-glucans with a $\beta(1,3)$-glucose backbone structure and $\beta(1,2)$-linked side-branches, which are found to be implicated in bacterial virulence (McIntosh et al., 2005).

Microbial $\beta$-glucans can be part of microbial cell wall (structural polysaccharides), intracellularly accumulated (storage polysaccharides used as carbon source), or exocellularly excreted to form protection layers around the cell wall (capsular polysaccharides) or loose slime biofilms of exopolysaccharide (EPS) (Karunaratne, 2012; Lee et al., 2016).

In general, either linear, cyclic or branched, $\beta$ glucans play a significant role in the bacterial tolerance to several stresses and, consequentially, in adaptation to the environment (Caggianiello et al., 2016; Stack et al., 2010). The intrinsic ability to produce $\beta$-glucans characterizes also several bacterial strains claimed for their probiotic features (Fanning et al., 2012). The production of $\beta$-glucans is considered an intriguing trait for probiotics as they improve their capability to tolerate the gastrointestinal transit, to modulate the immune response of the host and to contrast the pathogenic bacteria in the human gut (Remus et al., 2012; Stack et al., 2010). 
$\beta$-Glucans are also localized in the cell wall of yeast and fungi, where they confere rigidity and backing (Robledo-Briones and Ruiz-Herrera, 2013). In these organisms, the strength of $\beta$-glucan backbone is ensured by $\beta(1,3)$-D-glycopyranosyl residues with high (yeast) or low (fungi) degree of polymerization (Synytsya and Novák, 2013; Petravić-Tominac et al., 2010). The structure of side branches is highly variable; $\beta(1,3)$ - or $\beta(1,6)$-D-glycopyranosyl linkages can be found both in fungi and yeast (Chen and Seviour, 2007). Moreover, $\beta$ glucans occur in some plants, being usually contained in the endosperm cell walls and in the subaleurone layer of several cereals, such as oat, barley, sorghum, triticale, wheat and rice. $\beta$-Glucans from such species generally exhibit a linear chemical structure with $\beta(1,3)$ - and $\beta(1,4)$-D-glycopyranosyl residues, with $\beta(1,2)$ - or $(1,6)$ glucopyranosyl branches units (Barsanti et al., 2011).

\section{B-Glucans and their Physiological Activities}

$\beta$-Glucans from bacteria, fungal, yeast and vegetal sources, share the anomeric configurations of the $\beta$ glycosidic bonds, which connect the sugar residues. $\beta$ Linkages-containing sugars are non-digestible to humans, who lack the enzymes able to split such type of glycosidic bond (Barsanti et al., 2011). Despite their unsuitability for nutritional purposes, $\beta$-glucans own notable physiological effects which attract much attention and, at the same time, create skepticism. In fact, their physiological activities are connected to numerous factors which are not yet completely clarified. The biological effects of $\beta$-glucans seem to depend on some of their structural features, including their degree of polymerization, type of core and branch linkages, tridimensional conformation and solubility (Synytsya and Novák, 2013). Furthermore, some chemical modifications, such as sulfonylation, carboxymethylation, phosphorylation and acetylation, can determine an intensification of beneficial properties (Tranquilan-Aranilla et al., 2012; Jindal et al., 2013). Each of these aforementioned factors could influence a particular biological activity, including anticoagulant, antithrombotic, antioxidant, cholesterol reducing, anti-inflammatory, anti-cancer activities (Kagimura et al., 2015).

There are many evidences highlighting the ability of $\beta$-glucans to bind to macrophages and interact with specific receptors, thus provoking cascade of signals that influence the expression of genes involved in the regulation of apoptosis, cell proliferation and invasion (Novak and Vetvicka, 2009). Fungal $\beta$-glucans (principally from basidiomycetes) have long been used in traditional Chinese and Japanese medicines to treat and prevent human disease conditions (Chang, 2002; Kidd, 2000). In Japan, Lentinan, a glucan extracted from
Lentinula edodes and Polysaccharide $\mathrm{K}$ from Coriolus versicolor, are approved for use as immunoadjuvants for cancer therapy (Chihara et al., 1987), principally against gastric and colorectal (Nakano et al., 1999), prostate (Tari et al., 1994; Hazama et al., 2009) and breast (Kan et al., 1992) cancer. How glucans contrast carcinoma is not yet elucidated, although it can be supposed that they could bind the $\mathrm{COOH}$-terminal region of a subunit of Complement Receptor 3 (CR3) (Xia et al., 1999) and, plausibly, activate neutrophils or natural killer cells for cytotoxicity via complement activation by anti-tumor antibodies (Yan et al., 1999). Several studies hypothesized that the interaction between $\beta$-glucans and NK cells could inhibit the invasion of cancer cells (Volman et al., 2008). Some studies indicated that the solubility of these compounds is very important for anti-tumor activity, as more water soluble molecules are more active against cancer cells (Tao et al., 2006; Bohn and BeMiller, 1995). Studies on animal models indicated that several fungal $\beta$-glucans may also be helpful during chemotherapy and radiation treatments (Harada et al., 2002; Gu et al., 2005).

The efficacy of fungal glucans has been investigated also in the treatment of Alzheimer's disease, AIDS (Acquired Immunodeficiency Syndrome), multiple sclerosis and cardiovascular diseases (Kagimura et al., 2015). $\beta$-Glucans are even able to enhance the host defense against protozoa, bacteria, yeast and virus infections, such as those determined by Leishmania major, Candida albicans, Toxoplasma gondii, Staphylococcus aureus, Escherichia coli and Swine Influenza Virus (SIV) (Wiater et al., 2012; Vetvicka and Novak, 2011; Jung et al., 2004). $\beta$-Glucans from yeast have been ascribed the ability to absorb mycotoxins (such as zearalenon, aflatoxin B1, ochratoxin A and patulin), supposedly due to hydrogen bonds and van der Waals forces (Jouany et al., 2005; Shetty and Jespersen, 2006; Jung et al., 2004). The Minimum Inhibitory Concentration (MIC) value of $\beta$-glucans was investigated against several Gram-positive and Gram-negative bacteria, such as Bacillus megaterium, Enterococcus phoeniculicola, Klebsiella peneumoniae (Zhu et al., 2016). Fungal $\beta$-glucans extracted from Agaricus brasiliensis were shown to inhibit in vitro the replication of bovine herpes virus 1 (BoHV-1), probably by disturbing the viral penetration into host cells (Minari et al., 2011). Studies on animal models indicate that both cereal and fungal $\beta$-glucans can reduce blood cholesterol levels and exert a hypoglycemic effect (Dong et al., 2011; Sikora et al., 2013; Miranda-Nantes et al., 2011; Fukushima et al., 2001). The cholesterol lowering properties of oat $\beta$ glucans have been confirmed also by clinical studies and such fibers are currently used as ingredients of marketed functional food (Othman et al., 2011). The 
hypoglycemic effect is ascribable to glucan viscosity, which could determine a slower glucose absorption thought the gastrointestinal tract. In addition, the viscosity of $\beta$-glucans has been indicated to contribute to limit the insulin secretions (Wood, 2004; Brennan and Cleary, 2005) and to reduce the risk of coronary heart disease (FDA, 1997; Bell et al., 2001). These and other features render $\beta$-glucans particularly suitable for the formulation of functional food products and or supplements with health promoting effect such as the prevention of cardiovascular diseases, the facilitation of bowel motility and prevention of obstipation (Dongowski et al., 2002; Tsukada et al., 2003; Zhu et al., 2015).

Additionally, $\beta$-glucans display antioxidant properties that can be useful in anti-aging formulations for cosmetic preparations (Deng et al., 2012). Moreover, in in vivo studies, $\beta$-glucans were able also to stimulate both the collagen biosynthesis, through the activation of macrophages in healing wounds (Pillai et al., 2005), and the repairing of damaged tissues by enhancing the activity of macrophages, granulocytes and monocytes (Lee et al., 2003).

\section{$\beta$-Glucans and their Immune-Modulating Properties}

$\beta$-Glucans can be classified as Biological Response Modifiers (BRM) as they own the ability to influence physiological processes (Leung et al., 2006). BRM comprise various molecules including the large family of cytokines (the "messenger proteins" of the immune system) and, on the other hand, the immune-modulators, which can be either immunopotentiators or immunosuppressors (Novak and Vetvicka, 2008). $\beta$ Glucans from fungi, yeast, bacteria and cereals have been proved to be immunopotentiating functional molecules against pathogens and cancer (Brown and Gordon, 2003; Volman et al., 2008; Goodridge et al., 2009; Murphy et al., 2010). In vertebrates, fungal $\beta$ glucans have been demonstrated to activate leukocytes, thus increasing phagocytosis and the production of proinflammatory cytokines and chemokines (Smiderle et al., 2013). Additionally, the growth of several cancer cell lines were found to be inhibited by treatment with glucans in vitro (Chan et al., 2009), e.g., from prostate (Fullerton et al., 2000) and breast cancer (Vetvicka and Yvin, 2004). The anti-cancer ability of $\beta$-glucans is probably related to the enhancement of phagocytosis and proliferation of monocytes, granulocytes and macrophages, which have different glucan-binding receptors (e.g., TLR-2, Dectin-1 and CR3). Furthermore, chemokinesis, chemotaxis, degranulation, migration of macrophages are induced and intracellular processes, such as respiratory burst after phagocytosis of invading cells, activity of hydrolytic and metabolic enzymes, signaling processes leading to activation of other phagocytes, secretion of cytokines, are also demonstrated to be enhanced by $\beta$-glucans in several in vitro studies (Vetvicka and Vetvickova, 2012).

The conformational structure of $\beta$-glucans is apparently responsible for their immune-modulating and anti-cancer activity (Ross et al., 1999). More specifically, a backbone of $\beta(1,3)$-linkages associated to $\beta(1,6)$ branches seems to be the most effective coupling structure for immune stimulation, as it was found to enhance higher expression of proinflammatory cytokines in in vivo, in vitro and ex vivo trials (Chanput et al., 2012; Vannucci et al., 2013). Additionally, the degree of solubility (i.e., soluble, gelforming, or particle-forming), which depends in turn on the degree of polymerization, type of linkages, extent of branching and chemical derivation, is crucial in immune-modulation, as soluble glucans have been showed to strongly induce inflammatory cytokine production (Soltanian et al., 2009).

Anti-inflammatory activities of $\beta$-glucans from fungi were emphasized by other studies that proved their ability to significantly reduce NO production and secretion of TNF- $\alpha$ and IL-6 in LPS-stimulated macrophages (Jo et al., 2010). $\beta$-Glucans, from both fungi and yeast, were demonstrated to hinder the secretion of TNF- $\alpha$, IL- $1 \alpha$, IL- 1 and NO, decreasing the relative gene expression possibly via suppression of MAP kinases JNK1/2 and ERK1/2 (Xu et al., 2012a, $2012 b$ ). Alkali-treated $\beta$-glucans, showing single helical $3 \mathrm{D}$ conformation, enhanced, in vivo, IL- $1 \alpha$, IL- 6 , TNF- $\alpha$ and NO synthesis, contrarily to $\beta$-glucans with triple helical structure, thus highlighting the relevance of function-structure relationship in such compounds (Ohno et al., 1996). Moreover, $\beta$-glucans with a lower molecular weight were found to have higher activity in vivo, while higher molecular weight polymers were more active in vitro (Zhang et al., 2005).

Yeast $\beta$-glucans were able to reduce Prostaglandin E2 (PGE2) production, a prostanoid lipid mediator, during Th17 cell expansion (Gagliardi et al., 2010). Other authors found that baker's yeast $\beta$-glucans contrast oxidative stress in human blood platelets, which play a key role in inflammation process caused by LPS (Saluk et al., 2013). Some in vivo approaches have substantiated the anti-inflammatory potential of fungal $\beta$ glucans. Polysaccharide components of yeast cell wall (principally $\beta$-glucans) have been shown to alleviate intestinal inflammation in DSS-induced mice models (Jawhara et al., 2012). In humans, the anti-inflammatory effectiveness of $\beta$-glucans was investigated in different in vivo trials, which indicated a reduction of cytokine levels in whole blood from healthy volunteers, (Johnson et al., 2009), as well as in plasma and faeces from patients with chronic inflammatory bowel disease 
(Førland et al., 2011), after oral intake of $\beta$-glucans, principally from fungi.

\section{$\beta$-Glucans and Probiotics}

Probiotics, i.e., the beneficial microorganisms that positively influence the human health (FAO/WHO, 2002), include numerous strains of bacteria, mainly belonging to Bifidobacterium and Lactobacillus genera and yeast (Arena et al., 2014a). The beneficial actions for which they are claimed include the fortification of the intestinal mucosal barrier, the competition against pathogenic microflora, the ability to synthetize vitamins and short-chain fatty acids, the balancing action on the gut microbiota and the capability to stimulate host immune response by modulating the Gut Associated Lymphoid Tissue (GALT) (Scholz-Ahrens, 2016; van Baarlen et al., 2013). Besides probiotics, also prebiotic compounds are gaining increasing attention and popularity in nutritional science and among consumers. To be qualified as a prebiotic, a food ingredient should be non-digestible by humans but serve as fermentable substrate for specific, endogenous microorganisms of the gut micro flora. In this way, prebiotics can selectively stimulate the growth and/or activity of beneficial microorganisms, thus improving their health benefits to the host (Gibson et al., 2004). Hence, embracing the probiotics and prebiotics concepts, the term "synbiotic" denotes those products containing both probiotics and prebiotics, resulting in potential overall enhancement of the beneficial effects on health (Schrezenmeir and de Vrese, 2001; Paineau et al., 2014).

Most of the prebiotics currently used in the food industry comprise non-digestible oligosaccharides, such as inulin, Fructo-Oligosaccharides (FOS) and GalactoOligosaccharides (GOS). However, accumulating evidences indicate also $\beta$-glucans as potential source of prebiotics. $\beta$-Glucans could be comprised in prebiotic compounds because they meet the characteristics required to have this status. In fact, $\beta$-glucans are nondigestible through human gastrointestinal tract and numerous studies have shown their ability to selectively intensify probiotic action, including potentiation of immune-modulation, inhibition of cancer, reduction of cholesterol and decrease of cardiovascular disease (Arena et al., 2015; Patel et al., 2010; Patel and Goyal, 2012; Arena et al., 2016). In addition, $\beta$-glucans have been shown to be a carbon source for some probiotic microorganisms, influencing their growth rate and lactic acid production in the intestinal environment (Snart et al., 2006; Zhao and Cheung, 2011). Obviously, the ability to catabolize prebiotics, including $\beta$-glucans, is speciesand strain-dependent, as only some microorganisms have the necessary enzymatic pathways (Hughes et al., 2008; $\mathrm{Su}$ et al., 2007). Although little is known about how bacteria catabolize long chain, non-digestible fibers, numerous studies have showed that the fermentation of glucans could occur outside or inside the cell (Sarbini and Rastall, 2011). Moreover, in the complex environment of the gut microbiota, the fermentation of $\beta$-glucans is likey to occur by pathways involving metabolic cooperation mechanisms (Crittenden et al., 2002). Several gut commensals possess specific genes encoding for cell-associated glycosidases, which are assigned to hydrolyze monosaccharides from the nonreducing ends of oligo- and polysaccharides in the extracellular environment. Such enzymes work in association to ATP-Binding Cassette (ABC) transporters, permeases, proton symporters and PhosphoenolpyruvatePhosphotransferase (PEP- PTS) systems, which transport the hydrolyzed sugar into the cell (Katayama et al., 2005; Perrin et al., 2001). Other microorganisms are able to internalize long chain prebiotics into the cytoplasm via specific transport systems and then, catabolize them thought hydrolases, phosphorylases, epimerases, mutases and/or kinases (Bottacini et al., 2014; Pokusaeva et al., 2014). In the probiotic Bifidobacterium longum subsp. infantis, different metabolic pathways are activated, depending on which type of $\beta$-glucans occurs inthe growth medium. For instance, ABC transporter systems and PTS proteins, followed by intracellular glucanase, constitute the central pathways triggered with by $\beta$ glucans from barley and seaweed (Zhao and Cheung, 2013; Goh and Klaenhammer, 2015).

Interestingly, since the survival of probiotics is conditioned by the ability to pass through the gastrointestinal tract, particular attention has been focused on microorganisms able to produce exopolysaccharides, due to the ability of these compounds to increase the tolerance to acid and enzymatic stress (Stack et al., 2010; Caggianiello et al., 2016). Accordingly, food matrices containing barley $\beta$ glucans were also able to ameliorate the persistence of Lactobacillus strains to in vitro gastrointestinal transit (Arena et al., 2014a). Additionally, symbiotic mixtures of oat $\beta$-glucans and Bifidobacterium longum, Lactobacillus plantarum, or Lactobacillus paracasei have been shown to prolong the viability of these microorganisms within food matrices, such as yogurt and fermented skimmed milk (Rosburg et al., 2010; Kiliç and Akpinar, 2013; Lazaridou et al., 2014). Beside the prebiotic purpose, the addition of prebiotic compounds to food matrix could ameliorate functional, technological and organoleptic properties of food (Singh et al., 2012), albeit it remains necessary to individuate the most perform-ant synbiotic formulation (Vasiljevic et al., 2007; Zhao and Cheung, 2011; Hughes et al., 2008; Angelov et al., 2006; Kalpa and Preetha, 2016). Oat $\beta$ lucans were found to promote the viability of lactobacilli used for yogurt production and to have positive effects in terms of lactic acid content and $\mathrm{pH}$ reduction (Kilic and Kankaya, 2016). $\beta$-Glucans from microbial origin have 
been investigated for their prebiotic features and were proved to advantage Bifidobacterium spp., to decrease cholesterol levels in humans (Mårtensson et al., 2005) and to improve rheology and texture of fermented foods (Mårtensson et al., 2002). Moreover, a 2-substituted$(1,3)-\beta$-D-glucan of bacterial origin was shown to ameliorate in vitro the adhesion of Lactobacillus strains to the human intestinal epithelium, thus suggesting that it could contribute to improve colonization and persistence of probiotics into the host, with related beneficial effects (Russo et al., 2012). Food matrices containing barley $\beta$ glucans were reported to improve growth and probiotic features of different Lactobacillus strains during both unstressed conditions and after exposure to in vitro simulation of the digestive tract. In addition, $\beta$ glucans-containing food was shown to positively influence the adhesion of probiotics to human enterocytes in vitro (Arena et al., 2014b). Several researches have tried to determine the optimal ratio between prebiotics and probiotics in synbiotic formulations for hypocholesterolaemic and antihypertensive effects (Miremadi et al., 2016). Moreover, synbiotic functional foods have been found to beneficially change the profile of intestinal bacterial metabolites, including the enhancement of ketones, carbon disulfide methyl acetate and short chainfatty acids (Vitali et al., 2010).

A few studies have considered the impact of dietary $\beta$-glucans on the immunomodulatory properties of human probiotics. Chanput et al., (2012) demonstrated that $\beta$-glucans from different sources could modulate in vitro the expression of various human inflammationrelated genes, while earlier experiments on dendritic cells pointed to an anti-inflammatory potential of cereal $\beta$-glucans, suggesting they could contribute to immune homeostasis in the highly exposed intestinal environment (Wismar et al., 2011). Recently, we have investigated in vitro whether oat and barley $\beta$-glucans could influence the probiotic features of diverse lactobacilli strains as well as some aspect of their interaction with the host (Arena et al., 2016). Although no significant effect was found on bacterial survival to simulated digestive tract nor on microbial adhesion properties, interestingly, combinations of microorganisms and $\beta$-glucans could synergistically modulate the expression of several immune-related genes, resulting in an overall enhanced antiinflammatory effect of probiotics. The impact that $\beta$ glucans could have on immunomodulatory (as well as other) activities of probiotic bacteria highlights the therapeutic potential of dietary-based approaches for the treatment of gut immune dysfunctions. Therefore, studying the effects and the immune-modulating activity of combinations of $\beta$-glucans and probiotics on human host would deserve deeper researches.
In the aquaculture field, the scientific literature offers several contributions that deal with the effects of mixtures of $\beta$-glucans and probiotics on model organism. In one example, combination of yeast and vegetable $\beta$-glucans with probiotic Pseudomonas synxantha and Pseudomonas aeruginosa were able to beneficially influence the growth, survival and immune response of prawns (Penaeus latisulcatus) (Van Hai and Fotedar, 2009). Likewise, the combination of $\beta$-glucans isolated from algae and Shewanella putrefaciens strain, a probiotic isolated from gilthead seabream skin, was shown to modulate the immune response and stimulate growth of the gilthead seabream, i.e., up-regulating the transcriptional levels of IL-1 $\beta$ and INF $\gamma$ genes and down regulating $\operatorname{IgM}$ gene expression (Rodríguez et al., 2007). Such studies underlie the possibility to substantially improve breeding conditions and health status of farmed fishes (and so of consumers) by adequate dietary intervention.

\section{Concluding Remarks}

Synbiotic functional foods are obtaining large attention as they hold promising applications for health-promoting purpose. As documented by both in vitro and in vivo trials, $\beta$-glucans own several beneficial properties, including immuno-modulation, cancer and metastasis inhibition, anti-inflammatory activity, cholesterol reduction, digestion and constipation problem improvement and, interestingly, potentiation of probiotic effects, i.e., prebiotic activity. The prebiotic aptitude of $\beta$-glucans relies on their ability to positively influence growth rate and health-promotion effects of probiotic microorganisms. $\beta$-Glucans from different sources, e.g., microbial, fungal, yeast and cereal, have been isolated, purified and characterized in the last years, focusing on their commercial applicability alone and in combination with microorganisms. Such studies indicate that $\beta$-glucans have major characteristics to become profitable prebiotic ingredients of synbiotic food. Nonetheless, numerous aspects of their biological activity still need to be elucidated, as the complexity of the microbiota-host relationships is not easily outlined and predictable.

\section{Acknowledgment}

This work was supported by MIUR (PON02_00186_2937475) in the framework of the project named "protocolli innovativi per lo sviluppo di alimenti funzionali" (Pro. Ali. Fun.).

\section{Author's Contributions}

Mattia Pia Arena and Giuseppe Spano: Contribute in drafting the article and reviewing it critically for significant intellectual content. 
Daniela Fiocco: Give final approval of the version to be submitted and any revised version.

\section{Ethics}

Authors declares no ethical issues.

\section{References}

Angelov, A., V. Gotcheva, R. Kuncheva and T. Hristozova, 2006. Development of a new oatbased probiotic drink. Int. J. Food Microbiol., 112: 75-80. DOI: 10.1016/j.ijfoodmicro.2006.05.015

Arena, M.P., P. Russo, V. Capozzi, P. López and D. Fiocco et al., 2014a. Probiotic abilities of riboflavin-overproducing Lactobacillus strains: A novel promising application of probiotics. Applied Microbiol. Biotechnol., 98: 7569-7581.

DOI: $10.1007 / \mathrm{s} 00253-014-5837-\mathrm{x}$

Arena, M.P., G. Caggianiello, D. Fiocco, P. Russo and M. Torelli et al., 2014b. Barley $\beta$-glucanscontaining food enhances probiotic performances of beneficial bacteria. Int. J. Mol. Sci., 15: 3025-3039. DOI: $10.3390 /$ ijms 15023025

Arena, M.P., P. Russo, D. Fiocco, V. Capozzi and G. Spano, 2015. $\beta$-Glucans and Synbiotic Foods. In: Probiotics, Prebiotics and Synbiotics, Bioactive Foods in Promoting Health, Watson, R. and V. Preedy, (Eds.), Academic Press, pp: 423-433.

Arena, M.P., P. Russo, V. Capozzi, A. Rascón and G.E. Felis et al., 2016. Combinations of cereal $\beta$ glucans and probiotics can enhance the antiinflammatory activity on host cells by a synergistic effect. J. Funct. Foods, 23: 12-23.

DOI: $10.1016 /$ j.jff.2016.02.015

Barsanti, L., V. Passarelli, V. Evangelista, A.M. Frassanito and P. Gualtieri, 2011. Chemistry, physicochemistry and applications linked to biological activities of $\beta$-glucans. Nat. Prod. Rep., 28: 457-466. DOI: $10.1039 / \mathrm{C} 0 \mathrm{NP} 00018 \mathrm{C}$

Bell, S.J., R.A. Forse and B.R. Bistrian, 2001. U.S. Patent No. 6,210,686. Washington, DC: U.S. Patent and Trademark Office.

Bohn, J.A. and J.N. BeMiller, 1995. (1 $\rightarrow 3)-\beta-d-G l u c a n s$ as biological response modifiers: $A$ review of structure-functional activity relationships. Carbohydr. Polym., 28: 3-14. DOI: $10.1016 / 0144-8617(95) 00076-3$

Bottacini, F., M. Ventura, D. Van Sinderen and M. O'Connell Motherway, 2014. Diversity, ecology and intestinal function of bifidobacteria. Microb. Cell Fact., 13: 1-S4. DOI: 10.1186/1475-2859-13-S1-S4

Brennan, C.S. and L.J. Cleary, 2005. The potential use of cereal $(1 \rightarrow 3,1 \rightarrow 4)-\beta$-d-glucans as functional food ingredients. J. Cereal Sci., 42: 1-13.

DOI: $10.1016 /$ j.jcs.2005.01.002
Brown, G.D. and S. Gordon, 2003. Fungal $\beta$-glucans and mammalian immunity. Immunity, 19: 311-315. DOI: 10.1016/S1074-7613(03)00233-4

Caggianiello, G., M. Kleerebezem and G. Spano, 2016. Exopolysaccharides produced by lactic acid bacteria: From health-promoting benefits to stress tolerance mechanisms. Applied Microb. Biotechnol., 100: 3877-3886.

DOI: $10.1007 / \mathrm{s} 00253-016-7471-2$

Chang, R., 2002. Bioactive polysaccharides from traditional Chinese medicine herbs as anticancer adjuvants. J. Altern. Complement. Med., 8: 559-565. DOI: $10.1089 / 107555302320825066$

Chan, G.C., W.K. Chan and D.M. Sze, 2009. The effects of $\beta$-glucan on human immune and cancer cells. J. Hematol. Oncol., 2: 1-11.

DOI: $10.1186 / 1756-8722-2-25$

Chanput, W., M. Reitsma, L. Kleinjans, J.J. Mes and H.F. Savelkoul et al., 2012. $\beta$-glucans are involved in immune-modulation of THP-1 macrophages. Mol. Nutr. Food Res., 56: 822-833.

DOI: $10.1002 / \mathrm{mnfr} .201100715$

Chen, J. and R. Seviour, 2007. Medicinal importance of fungal $\beta-(1 \rightarrow 3),(1 \rightarrow 6)$-glucans. Mycol. Res., 111: 635-652. DOI: 10.1016/j.mycres.2007.02.011

Chihara, G., J. Hamuro, Y.Y. Maeda, T. Shiio and T. Suga et al., 1987. Antitumor and metastasisinhibitory activities of lentinan as an immunomodulator: An overview. Cancer Detect. Prev. Suppl., 1: 423-443. PMID: 3319150

Crittenden, R., S. Karppinen, S. Ojanen, M. Tenkanen and R. Fagerström et al., 2002. In vitro fermentation of cereal dietary fibre carbohydrates by probiotic and intestinal bacteria. J. Sci. Food Agric., 82: 781-789. DOI: $10.1002 /$ jsfa.1095

Deng, C., Z. Hu, H.T. Fu, M.H. Hu and X. Xu et al., 2012. Chemical analysis and antioxidant activity in vitro of a $\beta$-d-glucan isolated from Dictyophora indusiata. Int. J. Biol. Macromol., 51: 70-75. DOI: 10.1016/j.ijbiomac.2012.05.001

Dong, J., F. Cai, R. Shen and Y. Liu, 2011. Hypoglycaemic effects and inhibitory effect on intestinal disaccharidases of oat beta-glucan in streptozotocin-induced diabetic mice. Food Chem., 129: 1066-1071.

DOI: 10.1016/j.foodchem.2011.05.076

Dongowski, G., M. Huth, E. Gebhardt and W. Flamme, 2002. Dietary fiber-rich barley products beneficially affect the intestinal tract of rats. J. Nutr., 132: 3704-3714. PMID: 12468611

Fanning, S., L.J. Hall, M. Cronin, A. Zomer and J. MacSharry et al., 2012. Bifidobacterial surfaceexopolysaccharide facilitates commensal-host interaction through immune modulation and pathogen protection. Proc. Nat. Acad. Sci. USA, 109: 2108-2113. DOI: 10.1073/pnas.1115621109 
FAO/WHO, 2002. Guidelines for the evaluation of probiotics in food. Food and Agriculture Organization of United Nations and World Health Organization Working Group Report, London, Ontario.

FDA, 1997. FDA allows whole oat foods to make health claim on reducing the risk of heart disease. FDA Talk Paper Jan. 22, Food and Drug Administration, U.S. Department of Health and Human Services.

Førland, D.T., E. Johnson, L. Saetre, T. Lyberg and I. Lygren et al., 2011. Effect of an extract based on the medicinal mushroom Agaricus blazei Murill on expression of cytokines and calprotectin in patients with ulcerative colitis and Crohn's disease. Scand. J. Immunol., 73: 66-75. DOI: $10.1111 / \mathrm{j} .1365-3083.2010 .02477 . \mathrm{x}$

Fukushima, M., T. Ohashi, Y. Fujiwara, K. Sonoyama and M. Nakano, 2001. Cholesterol-lowering effects of maitake (Grifola frondosa) fiber, shiitake (Lentinus edodes) fiber and enokitake (Flammulina velutipes) fiber in rats. Exp. Biol. Med., 226: 758-765. PMID: 11520942

Fullerton, S.A., A.A. Samadi, D.G. Tortorellis, M.S. Choudhury and C. Mallouh et al., 2000. Induction of apoptosis in human prostatic cancer cells with beta-glucan (Maitake mushroom polysaccharide). Mol. Urol., 4: 7-13. PMID: 10851301

Futatsuyama, H., T. Yui and K. Ogawa, 1999. Viscometry of curdlan, a linear $(1 \rightarrow 3)-\beta$-D-glucan, in DMSO or alkaline solutions. Biosci. Biotech. Bioch., 63: 1481-1483. DOI: 10.1271/bbb.63.1481

Gagliardi, M.C., R. Teloni, S. Mariotti, C. Bromuro and P. Chiani et al., 2010. Endogenous PGE2 promotes the induction of human Th17 responses by fungal $\beta-$ glucan. J. Leukoc. Biol., 88: 947-954.

DOI: $10.1189 / \mathrm{jlb} .0310139$

Gay-Fraret, J., S. Ardissone, K. Kambara, W.J. Broughton and W.J. Deakin et al., 2012. Cyclic- $\beta$-glucans of Rhizobium (Sinorhizobium) sp. strain NGR234 are required for hypo-osmotic adaptation, motility and efficient symbiosis with host plants. FEMS Microbiol. Lett., 333: 28-36. DOI: $10.1111 / \mathrm{j} .1574-6968.2012 .02595 . \mathrm{x}$

Gibson, G., H. Probert, J. van Loo, R. Rastall and M. Roberfroid, 2004. Dietary modulation of the human colonic microbiota: Updating the concept of prebiotics. Nutr. Res. Rev., 17: 259-275. DOI: 10.1079/NRR200479

Goh, Y.J. and T.R. Klaenhammer, 2015. Genetic mechanisms of prebiotic oligosaccharide metabolism in probiotic microbes. Annual Rev. Food Sci. Technol., 6: 137-156. DOI: $10.1146 /$ annurev-food-022814-015706

Goodridge, H.S., A.J. Wolf and D.M. Underhill, 2009. $\beta$ glucan recognition by the innate immune system. Immunol. Rev., 230: 38-50.

DOI: $10.1111 /$ j.1600-065X.2009.00793.X
Gu, Y.H., Y. Takagi, T. Nakamura, T. Hasegawa and I. Suzuki et al., 2005. Enhancement of radioprotection and anti-tumor immunity by yeastderived $\beta$-glucan in mice. J. Med. Food, 8: 154-158. DOI: $10.1089 / \mathrm{jmf} .2005 .8 .154$

Harada, T., Miura, N.N., Adachi, Y., Nakajima, M., Yadomae, T. and N. Ohno, 2002. IFN- $\gamma$ induction by SCG, 1,3- $\beta$-D-glucan from Sparassis crispa, in $\mathrm{DBA} / 2$ mice in vitro. J. Interferon Cytokine Res., 22: 1227-1239. DOI: $10.1089 / 10799900260475759$

Hazama, S., S. Watanabe, M. Ohashi, M. Yagi and M. Suzuki et al., 2009. Efficacy of orally administered superfine dispersed lentinan for advanced pancreatic cancer. Hepatogastroenterology, 56: 240-244. PMID: 19453066

Hughes, S.A., P.R. Shewry, G.R. Gibson, B.V. McCleary and R.A. Rastall, 2008. In vitro fermentation of oat and barley derived $\beta$-glucans by human faecal microbiota. FEMS Microbiol. Ecol., 64: 482-493. DOI: $10.1111 / \mathrm{j} .1574-6941.2008 .00478 . x$

Jawhara, S., K. Habib, F. Maggiotto, G. Pignede and P. Vandekerckove et al., 2012. Modulation of intestinal inflammation by yeasts and cell wall extracts: Strain dependence and unexpected antiinflammatory role of glucan fractions. PLoS One, 7: e40648-e40648.

DOI: 10.1371/journal.pone.0040648

Jindal, M., V. Rana, V. Kumar, R.S. Singh and J.F. Kennedy et al., 2013. Sulfation of Aegle marmelos gum: Synthesis, physico-chemical and functional characterization. Carbohydr. Polym., 92: 1660-1668. DOI: 10.1016/j.carbpol.2012.11.032

Jo, W.S., Y.J. Choi, H.J. Kim, J.Y. Lee and B.H. Nam et al., 2010. The anti-inflammatory effects of water extract from Cordyceps militaris in murine macrophage. Mycobiology, 38: 46-51. DOI: $10.4489 / \mathrm{MYCO} .2010 .38 .1 .046$

Johnson, E., D.T. Førland, L. Saetre, S.V. Bernardshaw and T. Lyberg et al., 2009. Effect of an extract based on the medicinal mushroom Agaricus blazei Murill on release of cytokines, chemokines and leukocyte growth factors in human blood ex vivo and in vivo. Scand. J. Gastroenterol., 69: 242-250. DOI: $10.1111 /$ j.1365-3083.2008.02218.x

Jouany, J.P., A. Yiannikouris and G. Bertin, 2005. The chemical bonds between mycotoxins and cell wall components of Saccharomyces cerevisiae have been identified. Arch. Zootech., 8: 26-50.

Jung, K., Y. Ha, S.K. Ha, D.U. Han and D.W. Kim et al., 2004. Antiviral effect of Saccharomyces cerevisiae $\beta$-glucan to swine influenza virus by increased production of interferon- $\gamma$ and nitric oxide. J. Vet. Med., Series B, 51: 72-76.

DOI: $10.1111 /$ j.1439-0450.2004.00732.x 
Kagimura, F.Y., M.A.A. da Cunha, A.M. Barbosa, R.F. Dekker and C.R.M. Malfatti, 2015. Biological activities of derivatized D-glucans: A review. Int. J. Biol. Macromol., 72: 588-598.

DOI: 10.1016/j.ijbiomac.2014.09.008

Kalpa, R.E. and R. Preetha, 2016. Screening for suitable prebiotic for probiotic strain by in vitro fermentation. Biosci. Biotechnol. Res. Asia, 13: 1177-1181. DOI: $10.13005 / \mathrm{bbra} / 2149$

Kan, N., H. Kodama, T. Hori, A. Takenaka and T. Yasumura et al., 1992. Intrapleural treatment of breast cancer patients with pleural effusions: An analysis of 13 institutes in Kyoto and Shiga prefectures. Kyoto and Shiga breast cancer study group. Gan. Kagaku Ryoho., 19: 1632-1635. PMID: 1530322

Karunaratne, D.N., 2012. The complex world of polysaccharides. Tech Publishers, Rijeka.

Katayama, T., K. Fujita and K. Yamamoto, 2005. Novel bifidobacterial glycosidases acting on sugar chains of mucin glycoproteins. J. Biosci. Bioeng., 99: 457-465. DOI: $10.1263 / \mathrm{jbb} .99 .457$

Kidd, P.M., 2000. The use of mushroom glucans and proteoglycans in cancer treatment. Altern. Med. Rev., 5: 4-27. PMID: 10696116

Kiliç, G.B. and D. Akpinar, 2013. The effects of different levels of $\beta$-glucan on yoghurt manufactured with Lactobacillus plantarum strains as adjunct culture. J. Food Agric. Environ., 11: 281-287.

Kilic, G.B. and D.A. Kankaya, 2016. Assessment of technological characteristics of non-fat yoghurt manufactured with prebiotics and probiotic strains. J. Food Sci. Technol., 53: 864-871. DOI: $10.1007 / \mathrm{s} 13197-015-2055-1$

Kim, M.K., K.E. Ryu, W.A. Choi, Y.H. Rhee and I.Y. Lee, 2003. Enhanced production of $(1 \rightarrow 3)-\beta$ d-glucan by a mutant strain of Agrobacterium species. Biochem. Eng. J., 16: 163-168. DOI: $10.1016 / \mathrm{S} 1369-703 \mathrm{X}(03) 00032-9$

Komaniecka, I. and A. Choma, 2003. Isolation and characterization of periplasmic cyclic $\beta$-glucans of Azorhizobium caulinodans. FEMS Microbiol. Lett., 227: 263-269.

DOI: 10.1016/S0378-1097(03)00690-6

Lam, K.L. and P.C.K. Cheung, 2013. Non-digestible long chain beta-glucans as novel prebiotics. Bioact. Carbohydr. Diet. Fibre, 2: 45-64. DOI: $10.1016 /$ j.bcdf.2013.09.001

Lazaridou, A., A. Serafeimidou, C.G. Biliaderis, T. Moschakis and N. Tzanetakis, 2014. Structure development and acidification kinetics in fermented milk containing oat $\beta$-glucan, a yogurt culture and a probiotic strain. Food Hydrocol., 39: 204-214.

DOI: $10.1016 /$ j.foodhyd.2014.01.015
Lee, I.C., G. Caggianiello, I.I. van Swam, N. Taverne and M. Meijerink et al., 2016. Strain-specific features of extracellular polysaccharides and their impact on Lactobacillus plantarum-host interactions. Applied Environ. Microbiol., 82: 13 3959-3970. DOI: 10.1128/AEM.00306-16

Lee, S.B., H.W. Jeon, Y.W. Lee, K.W. Song and M.H. Park et al., 2003. Bio-artificial skin composed of gelatin and $(1 \rightarrow 3),(1 \rightarrow 6)-\beta$-glucan. Biomaterials, 24 : 2503-2511. DOI: 10.1016/S0142-9612(03)00003-6

Leung, M.Y.K., C. Liu, J.C.M. Koon and K.P. Fung, 2006. Polysaccharide biological response modifiers. Immunol. Lett., 105: 101-114. DOI: 10.1016/j.imlet.2006.01.009

Mårtensson, O., R. Öste and O. Holst, 2002. The effect of yoghurt culture on the survival of probiotic bacteria in oat-based, non-dairy products. Food Res. Int., 35: 775-784. DOI: 10.1016/S0963-9969(02)00074-1

Mårtensson, O., M. Biorklund, A.M. Lambo, M. Duenas-Chasco and A. Irastorza et al., 2005. Fermented, ropy, oat-based products reduce cholesterol levels and stimulate the bifidobacteria flora in humans. Nutr. Res., 25: 429-442. DOI: 10.1016/j.nutres.2005.03.004

McIntosh, M., B.A. Stone and V.A. Stanisich, 2005. Curdlan and other bacterial $(1 \rightarrow 3)-\beta$-D-glucans. Apply Microbiol. Biotech., 68: 163-173. DOI: $10.1007 / \mathrm{s} 00253-005-1959-5$

Minari, M.C., V.P. Rincão, S.A. Soares, N.M. Ricardo and C. Nozawa et al., 2011. Antiviral properties of polysaccharides from Agaricus brasiliensis in the replication of bovine herpesvirus 1. Acta Virol., 55: 255-259. PMID: 21978159

Miranda-Nantes, C.C., E.A. Fonseca, C.T. Zaia, R.F. Dekker and N. Khaper et al., 2011. Hypoglycemic and hypocholesterolemic effects of botryosphaeran from Botryosphaeria rhodina MAMB-05 in diabetes-induced and hyperlipidemia conditions in rats. Mycobiology, 39: 187-193. DOI: 10.5941/MYCO.2011.39.3.187

Miremadi, F., F. Sherkat and L. Stojanovska, 2016. Hypocholesterolaemic effect and anti-hypertensive properties of probiotics and prebiotics: A review. J. Funct. Foods, 25: 497-510. DOI: $10.1016 /$ j.jff.2016.06.016

Murphy, E.A., J.M. Davis and M.D. Carmichael, 2010. Immune modulating effects of $\beta$-glucan. Curr. Opin. Clin. Nutr. Metab. Care, 13: 656-661. DOI: $10.1097 / \mathrm{MCO} .0 \mathrm{~b} 013 \mathrm{e} 32833 \mathrm{flafb}$

Nakano, H., K. Namatame, H. Nemoto, H. Motohashi and Nishiyama et al., 1999. A multi-institutional prospective study of lentinan in advanced gastric cancer patients with unresectable and recurrent diseases: Effect on prolongation of survival and improvement of quality of life. Hepatogastroenterol., 46: 2662-2668. PMID: 10522061 
Novak, M. and V. Vetvicka, 2008. $\beta$-glucans, history and the present: Immunomodulatory aspects and mechanisms of action. J Immunotoxicol., 5: 47-57. DOI: $10.1080 / 15476910802019045$

Novak, M. and V. Vetvicka, 2009. Glucans as biological response modifiers. Endocr. Metab. Immune Disord. Drug Targets, 9: 67-75.

DOI: $10.2174 / 187153009787582423$

Ohno, N., T. Hashimoto, Y. Adachi and T. Yadomae, 1996. Conformation dependency of nitric oxide synthesis of murine peritoneal macrophages by betaglucans in vitro. Immunol. Letters, 53: 157-163. PMID: 8877412

Othman, R.A., M.H. Moghadasian and P. J. Jones, 2011. Cholesterol-lowering effects of oat $\beta$-glucan. Nutr. Rev., 69: 299-309. DOI: $10.1111 / j .1753-4887.2011 .00401 . x$

Paineau, D., F. Respondek, V. Menet, R. Sauvage and F. Bornet et al., 2014. Effects of short-chain fructooligosaccharides on faecal bifidobacteria and specific immune response in formula-fed term infants: A randomized, double-blind, placebocontrolled trial. J. Nutr. Sci. Vitaminol., 60: 167-175. DOI: $10.3177 /$ jnsv.60.167

Patel, S. and A. Goyal, 2012. The current trends and future perspectives of prebiotics research: A review. Biotech, 2: 115-125. DOI: 10.1007/s13205-012-0044-x

Patel, A.K., P. Michaud, R.R. Singhania, C.R. Soccol and A. Pandey, 2010. Polysaccharides from probiotics: New developments as food additives. Food Technol. Biotechnol., 48: 451-463.

Perrin, S., M. Warchol, J.P. Grill and F. Schneider, 2001. Fermentations of fructo-oligosaccharides and their components by Bifidobacterium infantis ATCC 15697 on batch culture in semi-synthetic medium. J. Applied Microbiol., 90: 859-865.

DOI: 10.1046/j.1365-2672.2001.01317.x

Petravić-Tominac, V., V. Zechner-Krpan, S. Grba, S. Srečec and I. Panjkota-Krbavčić et al., 2010. Biological Effects of Yeast $\beta$-Glucans. Agric. Conspec. Sci., 75: 149-158.

Pillai, R., M. Redmond and J. Röding, 2005. Antiwrinkle therapy: Significant new findings in the non-invasive cosmetic treatment of skin wrinkles with $\beta$-glucan. IFSCC Magazine, 8: 17-21. DOI: $10.1111 /$ j.1463-1318.2005.00268_3.x

Pokusaeva, K., G.F. Fitzgerald and D. Van Sinderen, 2014. Carbohydrate metabolism in bifidobacteria. Genes Nutr., 6: 285-306. DOI: $10.1007 / \mathrm{s} 12263-010-0206-6$

Remus, D.M., R. van Kranenburg, I.I. van Swam, N. Taverne and R.S. Bongers et al., 2012. Impact of 4 Lactobacillus plantarum capsular polysaccharide clusters on surface glycan composition and host cell signaling. Microb. Cell Fact., 11: 149-159.
Robledo-Briones, M. and J. Ruiz-Herrera, 2013. Regulation of genes involved in cell wall synthesis and structure during Ustilago maydis dimorphism. FEMS Yeast Res., 13: 74-84. DOI: $10.1111 / 1567-1364.12011$

Rodríguez, J., Y. Espinosa, F. Echeverría, G. Cárdenas and R. Román et al., 2007. Exposure to probiotics and $\beta-1,3 / 1,6$-glucans in larviculture modifies the immune response of Penaeus vannamei juveniles and both the survival to White Spot Syndrome Virus challenge and pond culture. Aquaculture, 273: 405-415.

DOI: $10.1016 / \mathrm{j}$.aquaculture.2007.10.042

Rosburg, V., T. Boylston and P. White, 2010. Viability of bifidobacteria strains in yogurt with added oat beta-glucan and corn starch during cold storage. J. Food Sci., 75: 439-444.

DOI: $10.1111 /$ j.1750-3841.2010.01620.x

Ross, G.D., V. Větvička, J. Yan, Y. Xia and J. Větvičková, 1999. Therapeutic intervention with complement and $\beta$-glucan in cancer. Immunopharmacology, 42: 61-74. DOI: 10.1016/S0162-3109(99)00013-2

Russo, P., P. López, V. Capozzi, P. Fernández de Palencia and M.T. Dueñas et al., 2012. Beta-Glucans improve growth, viability and colonization of probiotic microorganisms. Int. J. Mol. Sci., 13: 6026-6039. DOI: $10.3390 /$ ijms 13056026

Saluk, J., M. Bijak, M.B. Ponczek, P. Nowak and B. Wachowicz, 2013. ( $1 \rightarrow 3)-\beta$-d-Glucan reduces the damages caused by reactive oxygen species induced in human platelets by lipopolysaccharides. Carbohydr. Polym., 97: 716-724. DOI: 10.1016/j.carbpol.2013.05.054

Sarbini, S.R. and R.A. Rastall, 2011. Prebiotics: Metabolism, Structure and Function. Funct. Food Rev., 3: 93-106.

Scholz-Ahrens, K.E., 2016. Prebiotics, Probiotics, Synbiotics and Foods with Regard to Bone Metabolism. In: Nutritional Influences on Bone Health, Weaver, C.M., R.M. Daly and H.A. Bischoff-Ferrari (Eds.), Springer International Publishing, pp: 153-167.

Shetty, P.H. and L. Jespersen, 2006. Saccharomyces cerevisiae and lactic acid bacteria as potential mycotoxin decontaminating agents. Trends Food Sci. Tech., 17: 48-55. DOI: $10.1016 /$ j.tifs.2005.10.004

Schrezenmeir, J. and M. de Vrese, 2001. Probiotics, prebiotics and synbiotics-approaching a definition. Am. J. Clin. Nutr., 73: 361S-364S.

Sikora, P., S.M. Tosh, Y. Brummer and O. Olsson, 2013. Identification of high $\beta$-glucan oat lines and localization and chemical characterization of their seed kernel $\beta$-glucans. Food Chem., 137: 83-91. DOI: $10.1016 /$ j.foodchem.2012.10.007 
Singh, M., S. Kim and S.X. Liu, 2012. Effect of purified oat $\beta$-glucan on fermentation of set-style yogurt mix. J. Food Sci., 77: 195-201. DOI: $10.1111 / \mathrm{j} .1750-3841.2012 .02828 . \mathrm{x}$

Smiderle, F.R., G. Alquini, M.Z. Tadra-Sfeir, M. Iacomini and H.J. Wichers et al., 2013. Agaricus bisporus and Agaricus brasiliensis $(1 \rightarrow 6)-\beta$-d-glucans show immunostimulatory activity on human THP-1 derived macrophages. Carbohydr. Polym., 94: 91-99. DOI: 10.1016/j.carbpol.2012.12.073

Snart, J., R. Bibiloni, T. Grayson, C. Lay and H. Zhang et al., 2006. Supplementation of the diet with high-viscosity beta-glucan results in enrichment for lactobacilli in the rat cecum. Applied Environ. Microbiol., 72: 1925-1931. DOI: 10.1128/AEM.72.3.1925-1931.2006

Soltanian, S., E. Stuyven, E. Cox, P. Sorgeloos and P. Bossier, 2009. Beta-glucans as immunostimulant in vertebrates and invertebrates. Critical Rev. Microbiol., 35: 109-138. DOI: $10.1080 / 10408410902753746$

Stack, H.M., N. Kearney, C. Stanton, G.F. Fitzgerald and R.P. Ross, 2010. Association of beta-glucan endogenous production with increased stress tolerance of intestinal lactobacilli. Applied Environ. Microbiol., 76: 500-507. DOI: 10.1128/AEM.01524-09

Su, P., A. Henriksson and H. Mitchell, 2007. Selected prebiotics support the growth of probiotic monocultures in vitro. Anaerobe, 13: 134-139. DOI: $10.1016 /$ j.anaerobe.2007.04.007

Synytsya, A. and M. Novák, 2013. Structural diversity of fungal glucans. Carbohydr. Polym., 92: 792-809. DOI: 10.1016/j.carbpol.2012.09.077

Tao, Y., L. Zhang and P.C. Cheung, 2006. Physicochemical properties and antitumor activities of water-soluble native and sulfated hyperbranched mushroom polysaccharides. Carbohydr. Res., 341: 2261-2269. DOI: 10.1016/j.carres.2006.05.024

Tari, K., I. Satake, K. Nakagomi, K. Ozawa and F. Oowada et al., 1994. Effect of lentinan for advanced prostate carcinoma. Hinyokika Kiyo., 40: 199-123. PMID: 8128920

Tranquilan-Aranilla, C., N. Nagasawa, A. Bayquen and A.D. Rosa, 2012. Synthesis and characterization of carboxymethyl derivatives of kappacarrageenan. Carbohydr. Polym., 87: 1810-1816. DOI: 10.1016/j.carbpol.2011.10.009

Tsukada, C., H. Yokoyama, C. Miyaji, Y. Ishimoto and H. Kawamura et al., 2003. Immunopotentiation of intraepithelial lymphocytes in the intestine by oral administrations of $\beta$-glucan. Cellular Immunol., 221: 1-5. DOI: 10.1016/S0008-8749(03)00061-3

Van Baarlen, P., J.M. Wells and M. Kleerebezem, 2013. Regulation of intestinal homeostasis and immunity with probiotic lactobacilli. Trends Immunol., 34: 208-215. DOI: 10.1016/j.it.2013.01.005
Van Hai, N. and R. Fotedar, 2009. Comparison of the effects of the prebiotics (Bio-Mos ${ }^{\circledR}$ and $\beta-1,3-\mathrm{D}$ glucan) and the customised probiotics (Pseudomonas synxantha and P. aeruginosa) on the culture of juvenile western king prawns (Penaeus latisulcatus Kishinouye, 1896). Aquaculture, 289: 310-316. DOI: 10.1016/j.aquaculture.2009.02.001

Vannucci, L., J. Krizan, P. Sima, D. Stakheev and F. Caja et al., 2013. Immunostimulatory properties and antitumor activities of glucans (Review). Int. J. Oncol., 43: 357-364. DOI: 10.3892/ijo.2013.1974

Vasiljevic, T., T. Kealy and V.K. Mishra, 2007. Effects of $\beta$-glucan addition to a probiotic containing yogurt. J. Food Sci., 72: 405-411. DOI: $10.1111 /$ j.1750-3841.2007.00454.x

Vetvicka, V. and J.C. Yvin, 2004. Effects of marine $\beta-1,3$ glucan on immune reactions. Int. Immunopharmacol., 4: 721-730. DIOI: 10.1016/j.intimp.2004.02.007

Vetvicka, V. and M. Novak, 2011. Biological Actions of $\beta$-Glucan. In: Biology and Chemistry of Beta Glucan, Vetvicka, V. and M. Novak (Eds.), Bentham Science Publishers, pp: 10-18.

Vetvicka, V. and J. Vetvickova, 2012. $\beta$ 1, 3-glucan in cancer treatment. Am. J. Immunol., 8: 38-43. DOI: 10.3844 /ajisp.2012.38.43

Vitali, B., M. Ndagijimana, F. Cruciani, P. Carnevali and M. Candela et al., 2010. Impact of a synbiotic food on the gut microbial ecology and metabolic profiles. BMC Microbiol., 10: 153-167. DOI: $10.1186 / 1471-2180-10-4$

Volman, J.J., J.D. Ramakers and J. Plat, 2008. Dietary modulation of immune function by $\beta$-glucans. Physiol. Behav., 94: 276-284. DOI: 10.1016/j.physbeh.2007.11.045

Wiater, A., R. Paduch, A. Choma, M. Pleszczyńska and M. Siwulski et al., 2012. Biological study on carboxymethylated $(1 \rightarrow 3)$ - $\alpha$-d-glucans from fruiting bodies of Ganoderma lucidum. Int. J. Biol. Macromol., 51: 1014-1023. DOI: 10.1016/j.ijbiomac.2012.08.017

Wismar, R., S. Brix, H.N. Laerke and H. Frøkiaer, 2011. Comparative analysis of a large panel of non-starch polysaccharides reveals structures with selective regulatory properties in dendritic cells. Mol. Nutr. Food Res., 55: 443-454. DOI: $10.1002 / \mathrm{mnfr} .201000230$

Wood, P.J., 2004. Relationships between solution properties of cereal $\beta$-glucans and physiological effects-a review. Trends Food Sci. Technol., 15: 313-320. DOI: 10.1016/j.tifs.2003.03.001

Xia, Y., V. Větvička, J. Yan, M. Hanikýřová and T. Mayadas et al., 1999. The beta-glucan-binding lectin site of mouse CR3 (CD11b/CD18) and its function in generating a primed state of the receptor that mediates cytotoxic activation in response to iC3b-opsonized target cells. J. Immunol., 162: 2281-2290. PMID: 9973505. 
Xu, X., M. Yasuda, M. Mizuno and H. Ashida, 2012a. $\beta$ Glucan from Saccharomyces cerevisiae reduces lipopolysaccharide-induced inflammatory responses in RAW264.7 macrophages. Biochim. Biophys. Acta, 1820: 1656-1663.

DOI: 10.1016/j.bbagen.2012.06.015

$\mathrm{Xu}, \mathrm{X}$., M. Yasuda, S. Nakamura-Tsuruta, M. Mizuno and H. Ashida, 2012b. B-Glucan from Lentinus edodes inhibits nitric oxide and tumor necrosis factor- $\alpha$ production and phosphorylation of mitogenactivated protein kinases in lipopolysaccharidestimulated murine RAW 264.7 macrophages. J. Biol. Chem., 287: 871-878. DOI: $10.1074 /$ jbc.M111.297887

Yan, J., V. Větvička, Y. Xia, A. Coxon and M.C. Carroll et al., 1999. Beta-glucan, a "specific" biologic response modifier that uses antibodies to target tumors for cytotoxic recognition by leukocyte complement receptor type 3 (CD11b/CD18). J. Immunol., 16 3: 3045-3052. PMID: 10477568

Zhang, L., X. Li, and F. Zheng, 2005. Correlation between antitumor activity, molecular weight and conformation of lentinan. Carbohydr. Res., 340: 1515-1221. DOI: 10.1016/j.carres.2005.02.032
Zhao, J. and P.C.K. Cheung, 2011. Fermentation of $\beta$ glucans derived from different sources by bifidobacteria: Evaluation of their bifidogenic effect. J. Agricul. Food Chem., 59: 5986-5992. DOI: $10.1021 /$ jf200621y

Zhao, J. and P.C.K. Cheung, 2013. Comparative proteome analysis of Bifidobacterium longum subsp. infantis grown on $\beta$-glucans from different sources and a model for their utilization. J. Agric. Food Chem., 61: 4360-4370. DOI: 10.1021/jf400792j

Zhu, F., B. Du, Z. Bian and B. Xu, 2015. Beta-glucans from edible and medicinal mushrooms: Characteristics, physicochemical and biological activities. J. Food Compos. Anal., 41: 165-173. DOI: $10.1016 /$ j.jfca.2015.01.019

Zhu, F., B. Du and B. Xu, 2016. A critical review on production and industrial applications of betaglucans. Food Hydrocolloids, 52: 275-288. DOI: 10.1016/j.foodhyd.2015.07.003 